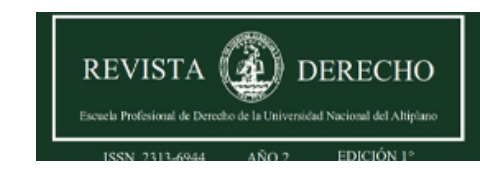

Revista de Derecho

ISSN: 2313-6944

ISSN: 2707-9651

revistaderecho@unap.edu.pe

Universidad Nacional del Altiplano

Perú

\title{
ESTUDIO CRIMINOLÓGICO SOBRE LA VIOLACIÓN DE LAS MEDIDAS SANITARIAS EN LA REGIÓN PUNO
}

Flores Tintaya, Claudia Ximena; Paredes Aceituno, Diana Alejandra; Luque Mendoza, Gerson; Apaza Quispe, Juliet Leslie; Mamani Larico, Leidy Gimena; Flores Mamani, Rosario

ESTUDIO CRIMINOLÓGICO SOBRE LA VIOLACIÓN DE LAS MEDIDAS SANITARIAS EN LA REGIÓN PUNO

Revista de Derecho, vol. 6, núm. 2, 2021

Universidad Nacional del Altiplano, Perú

Disponible en: https://www.redalyc.org/articulo.oa? $\mathrm{id}=671870938011$

DOI: https://doi.org/10.47712/rd.2021.v6i2.151

\section{(c) (1)}

Esta obra está bajo una Licencia Creative Commons Atribución 4.0 Internacional. 


\section{ESTUDIO CRIMINOLÓGICO SOBRE LA VIOLACIÓN DE LAS MEDIDAS SANITARIAS EN LA REGIÓN PUNO}

\section{CRIMINOLOGICAL STUDY ON THE VIOLATION OF SANITARY MEASURES IN THE REGION OF PUNO}

Claudia Ximena Flores Tintaya

Universidad Nacional del Altiplano Puno, Perú

lawclauxft5@gmail.com

(iD) https://orcid.org/0000-0002-7076-8344

Diana Alejandra Paredes Aceituno

Universidad Nacional del Altiplano Puno, Perú

paredesaceitunoalejandra@gmail.com

(iD) https://orcid.org/0000-0002-7594-5813

Gerson Luque Mendoza

Universidad Nacional del Altiplano Puno, Perú

gersonluquemendoza@gmail.com

(iD https://orcid.org/0000-0001-5298-0643

Juliet Leslie Apaza Quispe

Universidad Nacional del Altiplano, Perú

julietderecho1b@gmail.com

(iD) https://orcid.org/0000-0002-9008-3051

Leidy Gimena Mamani Larico

Universidad Nacional del Altiplano, Perú

leydigimena2000@gmail.com

(iD https://orcid.org/0000-0002-3291-3563

Rosario Flores Mamani

Universidad Nacional del Altiplano, Perú

floresmama7@gmail.com

(iD https://orcid.org/0000-0002-2823-0233
DOI: https://doi.org/10.47712/rd.2021.v6i2.151

Redalyc: https://www.redalyc.org/articulo.oa? $\mathrm{id}=671870938011$
Recepción: 05 Marzo 2021 Aprobación: 03 Agosto 2021 Publicación: 04 Agosto 2021

\section{RESUMEN:}

En este artículo, trataremos de explicar, haciendo una aproximación, las razones del comportamiento social peruano en tiempos de pandemia. Para lo cual se empezará con nociones teóricas sobre comportamiento, psicología social, comportamiento criminal, psicología criminal y derecho penal. Así como se utiliza al instrumento estadístico para obtener datos cuantitativos y así poder tener una aproximación en la identificación de los factores que conducen a la violación de medidas sanitarias, se presentan los resultados de encuestas con preguntas que tratan sobre temas de índole psicológico y económico.

Palabras claVe: Criminología, estudio, medidas, sanitarias.

\section{Abstract:}


In this article, we will try to explain, making an approximation, the reasons for Peruvian social behavior in times of pandemic. For which it will begin with theoretical notions on behavior, social psychology, criminal behavior, criminal psychology and criminal law. As well as the statistical instrument is used to obtain quantitative data and thus be able to achieve an approximation in the identification of the factors that lead to the violation of sanitary measures. The results of surveys are presented with questions that deal with psychological and economic issues.

KEYWORDS: Criminology, study, measures, sanitary.

\section{INTRODUCCIÓN}

El mundo entero está sufriendo una metamorfosis profunda de lo que se consideraba una normalidad, debido a la pandemia que nos obliga entre muchas cosas, a cambiar patrones de comportamiento para preservar un bien supraindividual, la salud pública.

En nuestro país se ha optado por diversas disposiciones de salubridad para contrarrestar el incremento de contagios de la enfermedad de la covid-19 las cuales fueron catalogadas de ineficaces por un gran sector de la población ya que tuvieron como resultado que, a mediados de agosto del 2020, Perú llegó a ser el Estado con la mayor mortalidad del mundo, y en ese punto tan complicado, es cuando un ciudadano se cuestiona cuáles son las razones que nos han conducido a posicionarnos en una situación tan precaria como esa. Una de las posibles causales, más allá de la ineficiencia de las medidas sanitarias, sería el propio comportamiento de la población siendo este, uno de los principales determinantes para la ineficacia de las medidas dictadas.

A partir de esta situación, este artículo trata de hacer un alcance en cuanto a la justificación conductual de los ciudadanos al incurrir estos, en la violación de las medidas sanitarias que fueron establecidas por el Gobierno siendo éste el objeto de estudio y análisis del presente trabajo, tomando como fundamento:

Primero, la psicología social siendo esta una rama mayormente teórica mediante la cual se buscará dar una explicación al comportamiento de la sociedad en el contexto de la pandemia. Segundo, por medio de la psicología criminal se tratará de dar a conocer la razón por la que el individuo recae en la concurrencia de la conducta antisocial buscando establecer el significado de dicha conducta y el por qué la punición no lo intimida, y en consecuencia no logra prescindir de sus conductas delictivas antisociales. Tercero, a través de la criminología conductual se busca entender la adaptación y desadaptación a la coyuntura social actual a raíz de la nueva normalidad, para ello se examinará y analizará el proceder de la sociedad. Finalmente, el Estado peruano sanciona estas conductas a través del Derecho Penal las cuales se subsumen en el Artículo 292 referido al Delito de la Violación de medidas sanitarias.

\section{MARCO TEÓRICO}

\section{a. COMPORTAMIENTO SOCIAL}

El comportamiento social o conducta social es el conjunto de actuaciones desarrolladas por un sujeto las cuales van dirigidas a la colectividad en cuanto ésta se refiere a su propia especie para generar influencia. Asimismo, para emprender su estudio se requiere conexionarlas con normas, valores y costumbres auténticos de la cultura en la que se presentan. Por ello se dice que lo idóneo o contraproducente del deber de comportamiento social se dan en justificación al contexto donde se desarrolla.(Puerta Rodriguez, 2020)

Entre los tipos de conducta se encuentra la denominada antisocial la cual describe el proceder de un sujeto, que va en contra del bienestar del resto de sus análogos; por lo que esta clase de comportamientos es sancionada al ir en contra de la sociedad, y entre ellos como ejemplo por excelencia se encuentra la mayoría de delitos.

Actualmente la enfermedad producida por el SARS-CoV-2 con un año aproximadamente de presencia en la vida de los seres que habitan el planeta, ha significado un cambio radical respecto de lo que era la concepción de normalidad para la humanidad porque lo ocasionado por ese microbio, vale decir cuarentenas 
(como ejemplo), que implican densos límites a los derechos, son incidentes agudos, estresantes, imprevistos lo que ha ocasionado la una interrupción en los procesos regulatorios de la vida social. (Ritchie \& Gill, 2011) Pandemias como la COVID-19, son desastres de la biosfera en los que los microorganismos pueden cambiar o evolucionar y potencialmente conducir a una pérdida significativa de vidas, que es precisamente lo que está aconteciendo y lo que se busca prevenir o en su caso disminuir a través de confinamientos. (Hodgkinson $\&$ Andresen, 2020)

Ahora bien, el caso de nuestro país, Perú es bastante particular pues la conducta adoptada por la ciudadanía durante los primeros meses de la presencia de la pandemia, fue cambiando, con un inicio positivo acompañado de una declaratoria de emergencia temprana, a un desarrollo no tan eficaz como en el principio. Jorge Yamamoto menciona que esto se debe a un problema de comportamiento más que de lógica, una indisciplina social que realmente no es nueva en la idiosincrasia, asegura que, si en el mundo ha sido un tema difícil de controlar, en el Perú es triplemente complicado lograrlo, por la misma naturaleza de su gente. (Valdivia Velez, 2020)

\section{b. PSICOLOGÍA SOCIAL}

La psicología social estudia las relaciones sociales que se dan a base de la interacción, y como están influyen y van a modificar la conducta, los sentimientos, los pensamientos del ser humano.

Crespo Suarez (1995) afirma: "La psicología social se entiende como fruto de un trabajo teórico y epistemológico que, como tal, siempre está abierto”. Este autor nos muestra que la psicología social es el resultado de la interacción de una sumatoria entre conceptos de sociedad, materia, consciencia, etc. y la conexión de unos con otros.

La psicología social abarca tanto solo al individuo como al grupo (sociedad), que como comprensión en general va concatenar al tratamiento de este como reacción frente a su medio y frente a su propio pensamiento individual. Por su parte si hacemos una articulación entre lo que es la psicología y lo social algunos autores tal como señala Thompson (1984), «el problema de la relación entre individuo y sociedad, entre la acción y la estructura social, yace en el corazón de la teoría social y de la filosofía de la ciencia social» (p. 148).

Por otro lado cuando hablamos de esa relación con la atribución de causalidad, juegan un importante papel para explicar la conducta individual de pasividad, apatía y aparente incapacidad para asumir las riendas de su propio destino y la transformación de su ambiente.(Montero, 2010)

Es preciso hacer una atingencia en cuanto a que la psicología actúa como un componente individual y este va conllevar a la división cada vez más específica, es decir, si a la psicología se le entiende como ciencia entonces a la psicología social se le va definir como una rama de tal ciencia. Y puesto que el objeto de una ciencia no es una cosa, sino un tipo de relación (Bateson, 1979), se va expresar claramente qué relación o tipo de conexión van a existir entre la una con la otra. Además, como disciplina de una ciencia tenemos muchos aportes, pero lo más iterativo es la frecuencia con que muchos la señalan como estudio de la conducta humana. Cabe recalcar que existen diversas apreciaciones en cuento a estas afirmaciones, pero las coincidencias dan un punto medio en el cual se explica a la psicología social como ente que estudia los pensamientos, las emociones, el comportamiento con el cual reaccionada un individuo.

\section{c. CRIMINOLOGIA CONDUCTUAL}

La criminología conductual carece de historia sistematizada, por eso se va tomar la historia de su precursora la psicología conductual y algunas opciones de juristas, psicólogos y criminólogos que aportan satos valiosos, pero como objeto de estudio de la conducta, de cómo los seres humanos aprenden a adaptarse o des adaptarse al medo que les rodea, viene siendo la ciencia del control social el cual se logra por medio de la relación estimulo-reforzado -respuesta: por ejemplo, qué estimula al sujeto a responder con un acto antisocial; de la misma manera sirve para observar y describir los factores criminógenos (estímulos) que influyen, poder predecir las consecuencias (refuerzos), en si viene siendo la ciencia del control social el cual se logra por medio de los estímulos y refuerzos, también ayuda a conocer los resultados de los efectos del castigo en la 
conducta de los individuos (penalidades) y los modelos de prevención por medio de reforzadores positivos y negativos(política criminológica). (DiCaprio, 1989)

El profesor en Psicología del Desarrollo de la Universidad de Georgia, David Shaffer señala que el Conductismo se define como: "escuela de pensamiento que sostiene que las conclusiones sobre el desarrollo humano deben basarse en observaciones controladas del comportamiento manifiesto en lugar de hacerlo en especulaciones sobre los motivos inconscientes u otros fenómenos inobservables (Shaffer, 1999)

La escuela psicológica que sostiene que la conducta se puede explicar principalmente a través de las interpretaciones psíquicas y luego de su interacción con el medio. Pero aunque el Conductismo se oponga al reconocimiento de los procesos internos, éste se ha convertido en una rama de la Psicología General y también puede ser definido como: "corriente de la Psicología que defiende el empleo de procedimientos estrictamente experimentales para estudiar el comportamiento observable (la conducta), considerando el entorno como un conjunto de estímulos-respuesta" (Mendoza Beivide, 2006)

\section{d. PSICOLOGÍA CRIMINAL}

La psicología criminal ha sido entendida tradicionalmente como la ciencia que estudia las causas y motivos, normales y/o patológicos que conducen a una persona a convertiste en un delincuente, se debe enfatizar que la psicología criminal es aquella vertiente de la psicología jurídica que agrupando diversas áreas de la misma intenta abordar la comprensión del fenómeno de la delincuencia, sus causas, efectos y tratamiento, con la finalidad de ayudar a su reducción mediante métodos preventivos o interventivos. (Soria Verde \& Roca Sáiz, 2005)

La psicología criminal es una rama aplicada de la psicología que manifiesta una relación entre diferentes variables psicológicas con la violación de la norma jurídica. Esta rama, tradicionalmente, se ocupa de la investigación del delincuente, cuales son las motivaciones de los delitos y; consecuentemente, las causas de la criminalidad. Ahora bien, esta rama estudia también los componentes estructurales del individuo, cual es la influencia que el recibe del entorno en donde él se desarrolla, y componentes como, edad, sexo y la personalidad. Por otro lado, haciendo mención al delito, entendiendo este como una afectación a las normas jurídicas, la psicología criminal vendría a realizar una descripción y explicación del porque se comete la vulneración a la norma.

El objeto de la Psicología Criminal es el estudio científico de los determinantes psicológicos del comportamiento antisocial y delictivo, para este fin, se formulan hipótesis y teorías psicológicas para la descripción y explicación del comportamiento delictivo, además de cuestiones asociadas a la prevención, resocialización y medidas pertinentes de terapéutica.

El interés de la Psicología Criminal se centra en todos aquellos factores psicológicos que pueden ayudar a describir, explicar y predecir el comportamiento antisocial o delictivo, su campo de estudio es muy amplio y abarca múltiples áreas, pero quizá sea en el ámbito de estudio de las diferencias individuales donde sus resultados han sido más productivos. (Corbolán Berná \& Patró Hernández, 2006)

\section{e. MEDIDAS SANITARIAS}

Las medidas sanitarias de seguridad (MSS) son un conjunto de actuaciones aplicadas por la autoridad sanitaria para, prevenir, mitigar, controlar o eliminar un evento que origine riesgos que afecten la salud de la población. (Invima, 1993)

Entonces una medida sanita impuesta por un determinado estado, es toda medida aplicada con la finalidad de protegerla vida y la salud de; personas y animales, personas de riesgo resultantes de la presencia de contaminaciones, personas de riesgos resultantes de enfermedades propagadas ya sea por animales, vegetales o de la propagación de una plaga. (El Diario del Exportador, 2017)

Las medidas sanitarias son aquellas destinadas a proteger la salud de las personas y vegetales, se aplican tanto a los artículos alimenticios o a las enfermedades y en esta coyuntura se hablará de una pandemia. (El Diario del Exportador, 2017)

\section{f. VIOLACIÓN A LA NORMA JURÍDICA}


Una norma jurídica es un mandato o regla que tiene como objetivo dirigir el comportamiento de las personas dentro de la sociedad, en tal sentido es preciso mencionar que:

"La norma jurídica es una regla u ordenación del comportamiento humano dictado por la autoridad competente del caso, con un criterio de valor y cuyo incumplimiento lleva a una sanción. Generalmente, impone deberes y confiere derechos. Se trata de una regla o precepto de carácter obligatorio, emanado de una autoridad normativa legitimizada, la cual tiene por objeto regular las relaciones sociales o la conducta del hombre que vive en sociedad" (Creosltda.com, n.d.)

¿POR QUÉ SE VIOLA O TRANSGREDE UNA NORMA JURÍDICA?

$\mathrm{Al}$ respecto, podemos sostener dos posiciones para tratar de responder tal interrogante.

1.- Contenido de Valor de la norma jurídica:

En virtud de esta posición, (Rodríguez Chávez) sostiene que las violaciones o transgresiones de las normas jurídicas no son sino el producto del contenido de valor que posean. Si el valor que contiene una norma jurídica es considerado como bueno por la comunidad, entonces, la norma jurídica será aceptada y, consecuentemente respetada por todos. En caso contrario, si el contenido de valor de una norma jurídica contradice el valor general, el valor común de la sociedad, entonces, devendrá inevitablemente la violación de la norma jurídica. En conclusión, del contenido de valor que posea la norma jurídica, dependerá su violación o transgresión, o en su caso, su respeto u observancia.

2.- Cultura violenta del hombre:

Una segunda posición de (Rodríguez Chávez) sostiene que el origen de tales violaciones radica en la cultura violenta del hombre. Desde que puso los pies sobre la tierra, el hombre siempre ha querido ir más allá de lo permitido, en la esencia misma del hombre se halla aquella inclinación por romper todo tipo de limitaciones, todo tipo de parámetros entre ellos las normas jurídicas que el hombre casi intuitivamente viola o transgrede. En tal sentido, al existir la norma jurídica, se convierte en una suerte de “manzana de Adán”, en una tentación que llama al hombre a violarla o simplemente no cumplirla.

\section{g. POLÍTICA CRIMINAL}

La política criminal es la línea de acción de todo gobierno (ya sea un régimen democrático o dictatorial) vinculadas a la prevención y acciones represivas ante los hechos punibles; de esta manera el Estado tienen la obligación de dar respuesta a conductas consideradas reprochables o causantes de perjuicio social. La definición de política criminal estaría atravesada por tres categorías: a) El objeto de intervención al cual se dirige la norma, la política, la estrategia o la medida. b) Los medios que se escogen para la intervención. c) Los fines que se persiguen con el catálogo de medidas en el marco de la política criminal como menciona. (Observatorio de Política Criminal, 2015)

La política criminal, debe enmarcarse en el respeto de los derechos fundamentales, y no en objetivos o cálculos electorales o de otra naturaleza incompatible, pese a ello lleva impreso lo principios e ideologías de quien detenta el poder, Por ello, el tratamiento del fenómeno criminal varía según la clase de Estado en la que se ubique. En ese sentido, la política criminal de un régimen democrático será totalmente distinta a la de un régimen totalitario, este último muchas veces influenciado por las ideologías de corte político.

\section{DATOS ESTADÍSTICOS}

Las estadisticas aplicadas a un segmento de la población buscan a través de las preguntas planteadas conocer los motivos y/o razones por las cuales el individuo viola las medidas sanitarias, impuestas por la autoridad durante la pandemia ocasionada por la Covid-19, ello a través de sesgos orientados al acercarmiento en lo posible a respuestas que nos aproximen a un entendimiento de las conductas para a traves de ellas poder plantear una nueva política criminal. 

SANI...

La encuesta fue realizada y enviada a ciudadanos de diversos rangos de edad (en el lapso de dos semanas), asumimos en su gran mayoria, personas originarias del departamento de Puno y todas ellas con mayoriade edad cumplida para encauzar al estudio del ciudadano que esta sujeto al ius puniendi del Estado.

a. CALIFICACIÓN DE LAS MEDIDAS SANITARIAS ADOPTADAS POR EL GOBIERNO DURANTE LA PANDEMIA

Con un número de 346 encuestados, en el siguiente cuadro se muestra la aceptación o no aceptación a las medidas sanitarias durante le estado de emergencia.

TABLA 1

Calificación de las Medidas Sanitarias

\begin{tabular}{lll}
\hline $\begin{array}{l}\text { ¿Cómo califica las medidas } \\
\text { sanitarias adoptadas por el Gobierno } \\
\text { durante la pandemia? }\end{array}$ & Frecuencia & Porcentaje \\
\hline Muy mala & 39 & \\
Mala & 155 & 11,3 \\
Buena & 148 & 44,8 \\
Muy buena & 4 & 42,8 \\
\hline \multicolumn{1}{c}{ Total } & 346 & 1,2 \\
\hline
\end{tabular}

Fuente: Elaboración propia

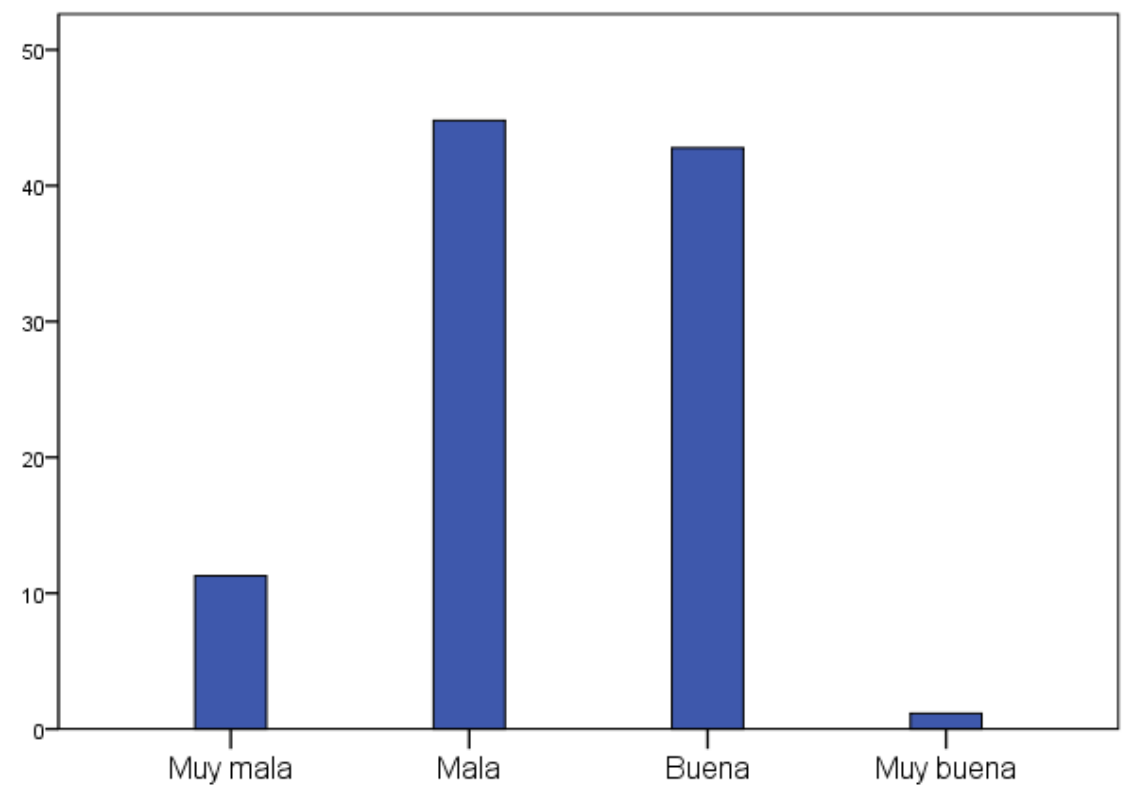

FIGURA 01

Calificación de las Medidas Sanitarias

Elaboración propia

Podemos resaltar de esta pregunta que, con un $56.1 \%$ la población ha percibido de forma negativa las medidas impuestas por el Gobierno mientras que un restante 43.9 las ha percibido de manera positiva. Nos encontramos ante una diferencia en un punto medio, ni muy amplia pero tampoco muy corta, que nos ayuda como punto de partida para el fin del presente trabajo. Como primera evidencia, queda entonces la imposición de la percepción negativa hacia las medidas lo cual probablemente orientaría a una desobediencia 
en términos coloquiales a la norma. Sin embargo, a través de las siguientes preguntas podremos encuadrar esto más detalladamente, pues la conducta puede no adecuarse a la percepción personal tomando en cuenta que la norma protege un fin de carácter supraindividual, colectivo.

TABLA 2

Afectación de la Cuarentena en la Situación Económica

\begin{tabular}{lll}
\hline $\begin{array}{l}\text { Su situación económica a partir del } \\
\text { inicio de la cuarentena (16 de marzo } \\
\text { del 2020), ¿se ha visto afectada? }\end{array}$ & Frecuencia & Porcentaje \\
\hline Nada & 16 & \\
Poco & 145 & 4,6 \\
Mucho & 185 & 41,9 \\
\hline \multicolumn{1}{c}{ Total } & 346 & 53,5 \\
\hline
\end{tabular}

Elaboración propia

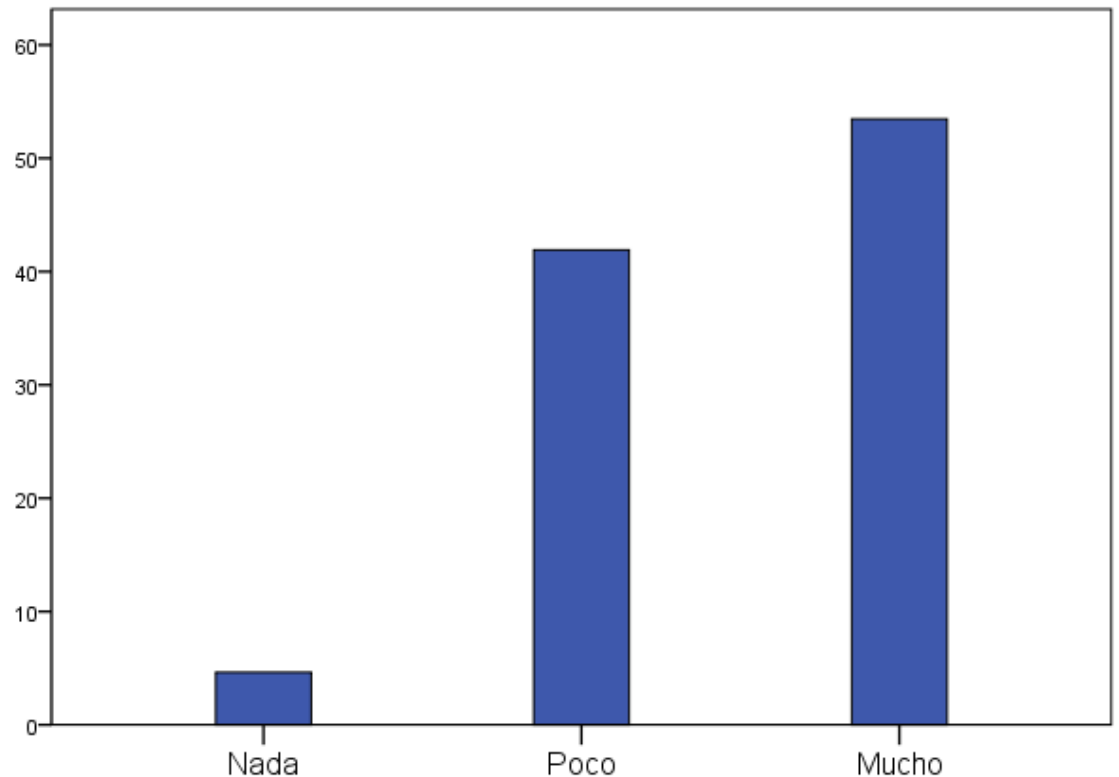

FIGURA 02

Afectación de la cuarentena en la situación económica

Elaboración propia

TABLA 3

Pérdida de Empleo

\begin{tabular}{|c|c|c|}
\hline $\begin{array}{l}\text { ¿Su ingreso económico depende de } \\
\text { una actividad diaria? }\end{array}$ & Frecuencia & Porcentaje \\
\hline Sí & 211 & 61,0 \\
\hline No & 135 & 39,0 \\
\hline Total & 346 & 100,0 \\
\hline
\end{tabular}

Elaboración propia 


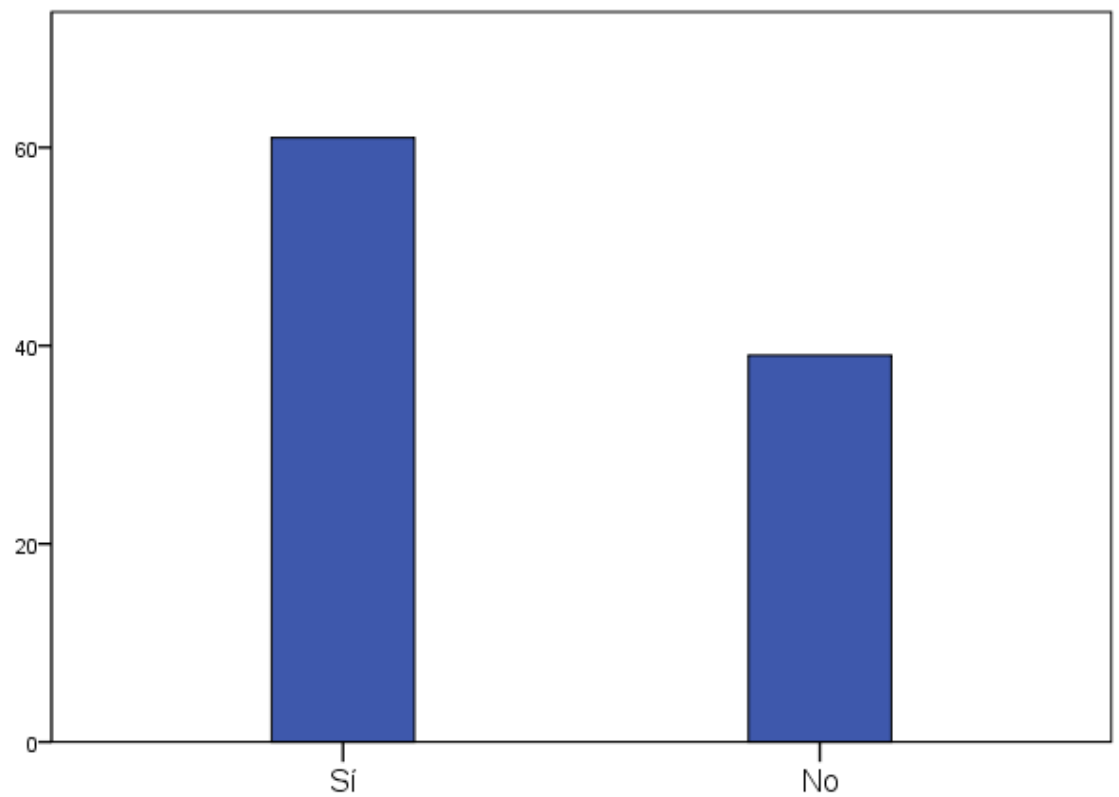

FIGURA 03

Pérdida de empleo

Elaboración propia

TABLA 4

La Manera de Ingreso Económico

\begin{tabular}{|c|c|c|}
\hline $\begin{array}{l}\text { ¿Su ingreso económico depende de } \\
\text { una actividad diaria? }\end{array}$ & Frecuencia & Porcentaje \\
\hline Sí & 210 & 60,7 \\
\hline No & 136 & 39,3 \\
\hline Total & 346 & 100,0 \\
\hline
\end{tabular}

Elaboración propia 


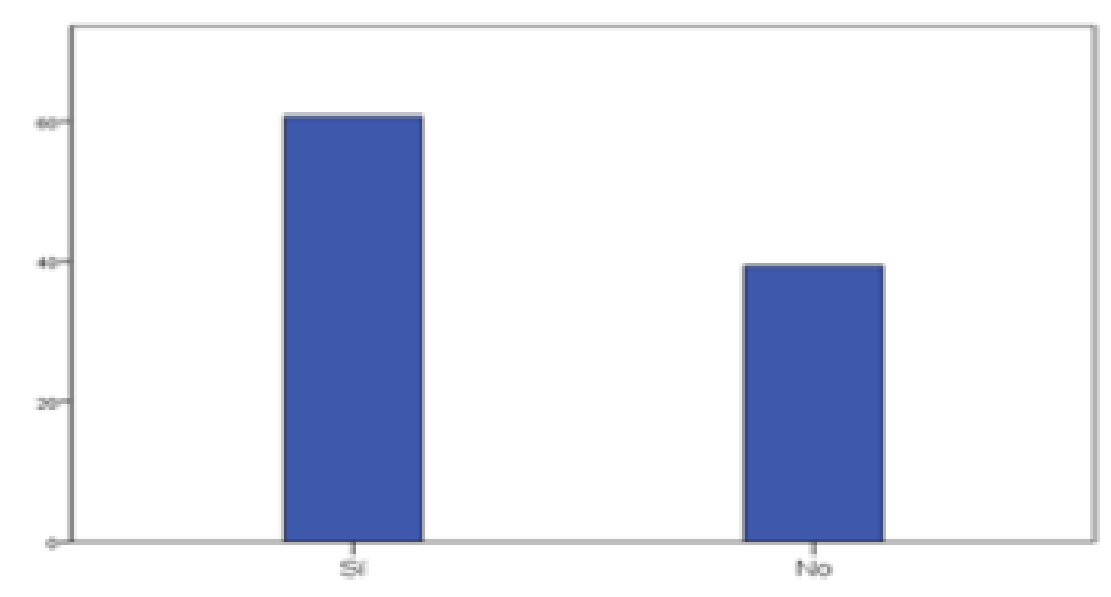

FIGURA 04

La manera de ingreso económico

Elaboración propia

El impacto económico que trajo la cuarentena en Puno fue tal que solamente el 4,6\% de las personas encuestadas no se vieron afectadas económicamente. sin embargo, la mayoría de encuestados (53.5\%) sí se han visto afectados considerablemente con las medidas impuestas por el Gobierno, cifra que se antepone al 41.9\% que han sido mínimamente afectados. A ello añadimos que según el cuadro $\mathrm{N}^{\circ} 3$ y el cuadro $\mathrm{N}^{\circ} 4$ se desprende que tres de cada cinco personas se han visto afectadas pues ellos mismos o en su mayoría sus familiares nucleares, han perdido su empleo (61\%) así como también su ingreso económico dependía de una actividad diaria (60.7\%).

Considerando las cifras anteriores se conjetura que los encuestados buscaron otros medios para suplir y poder alcanzar a los ingresos que tenían en tiempos pre-cuarentena y esto conlleva al desacato de las normas impuestas por el Gobierno.

TABLA 5

Actividades de Relajación

\begin{tabular}{lll}
\hline $\begin{array}{l}\text { ¿Su ingreso económico depende de } \\
\text { una actividad diaria? }\end{array}$ & Frecuencia & Porcentaje \\
\hline Realizar ejercicios físicos/deporte & 80 & 23,1 \\
$\quad$ Leer & 59 & 17,1 \\
Videojuegos & 44 & 12,7 \\
Mirar TV/ Streaming & 92 & 26,6 \\
Actividades artísticas & 43 & 12,4 \\
Reuniones virtuales con & 28 & 8,1 \\
familia/amigos & & \\
\hline \multicolumn{1}{c}{ Total } & 346 & 100,0 \\
\hline
\end{tabular}

Elaboración propia 


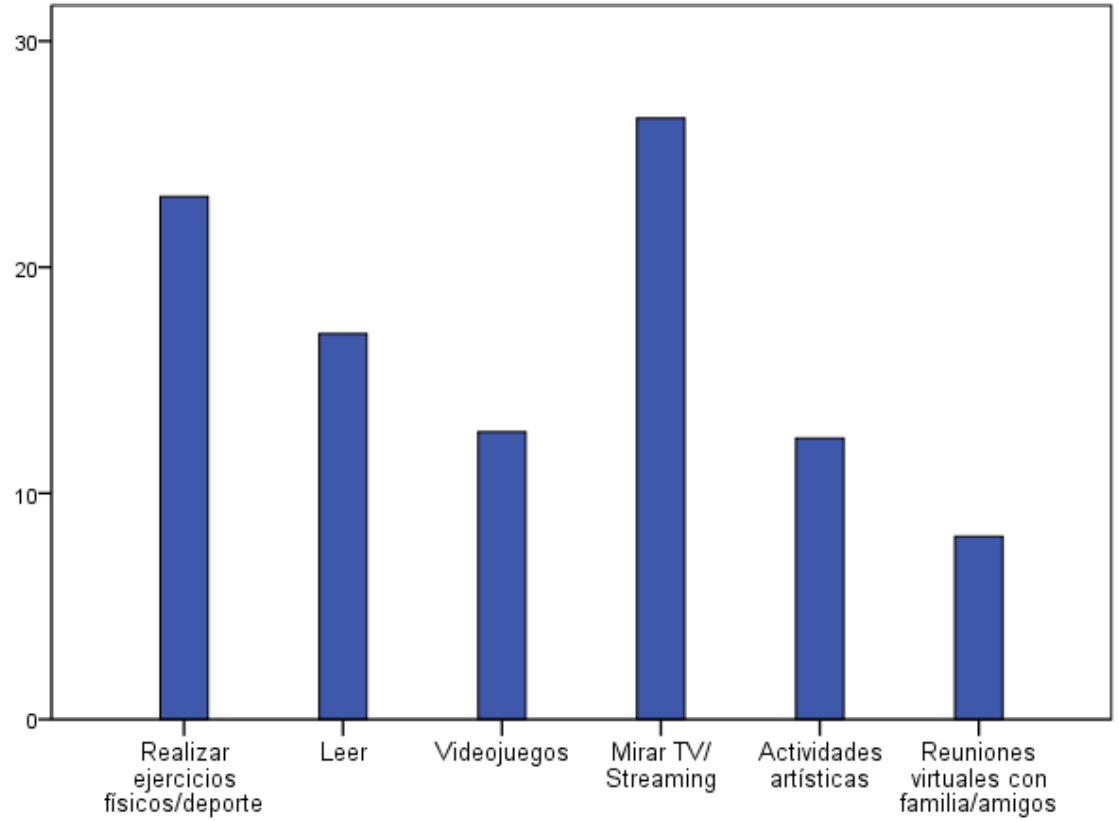

FIGURA 5

Actividades de relajación

Elaboración propia

TABLA 6

Reuniones Sociales

\begin{tabular}{lll}
\hline $\begin{array}{l}\text { ZAsistió de manera personal a algún } \\
\text { compromiso, fiesta, reencuentro o } \\
\text { cualquier otro análogo, a manera de } \\
\text { distracción? }\end{array}$ & Frecuencia & Porcentaje \\
\hline Sí & 148 & \\
No $\quad 198$ & 42,8 \\
\hline$\quad$ Total & 346 & 57,2 \\
\hline
\end{tabular}

Elaboración propia 


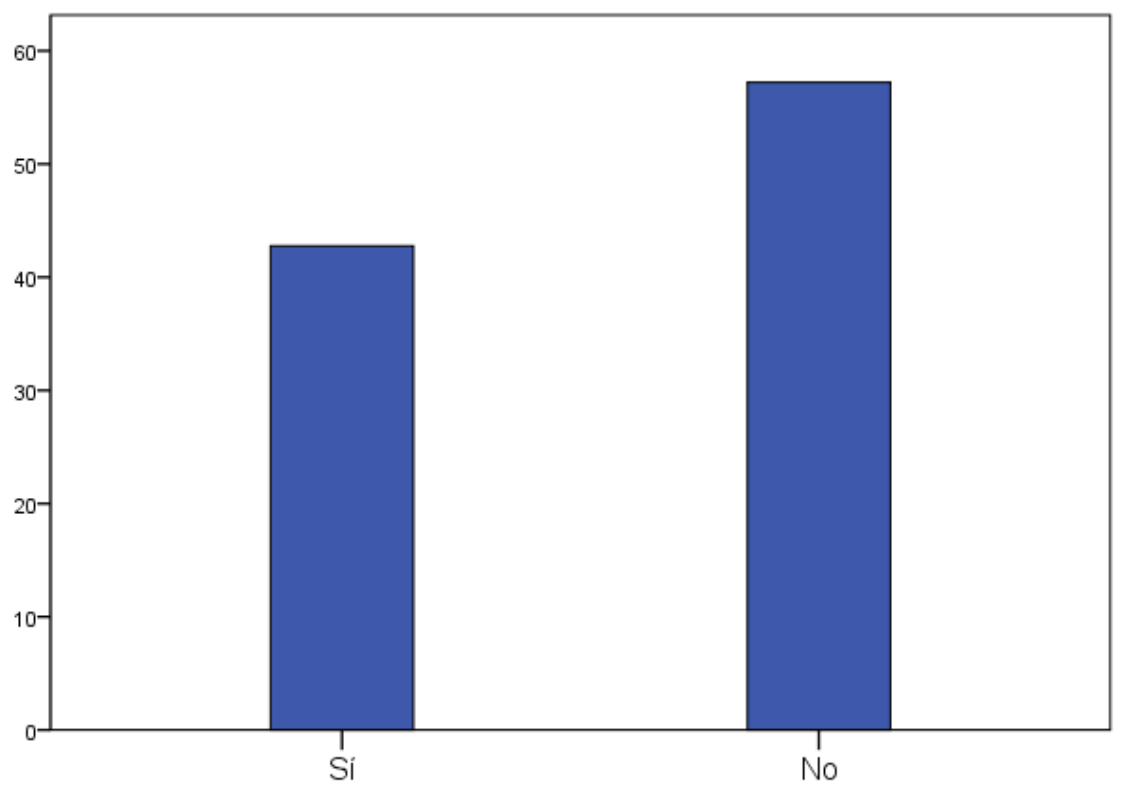

FIGURA 6

Reuniones Sociales

Elaboración propia

De otro lado, respecto a las actividades realizadas por los encuestados para relajarse de manera regular, se obtuvo que la mayoría (91.9\%) optó por realizar actividades individuales como realizar ejercicios físicos, leer, jugar videojuegos, consumir contenido televisivo o streaming y actividades artísticas todo ello. Además de ello, en el gráfico $\mathrm{N}^{\circ} 6$ que abarca el tema de la distracción a través de reuniones sociales se obtiene que tres de cada cinco personas no asistieron a un compromiso.

TABLA 7

Ansiedad y Estrés

\begin{tabular}{|c|c|c|}
\hline $\begin{array}{l}\text { ¿Sufrió de ansiedad o estrés durante } \\
\text { la Pandemia? }\end{array}$ & Frecuencia & Porcentaje \\
\hline Sí & 278 & 80,3 \\
\hline No & 68 & 19,7 \\
\hline Total & 346 & 100,0 \\
\hline
\end{tabular}

Elaboración propia 


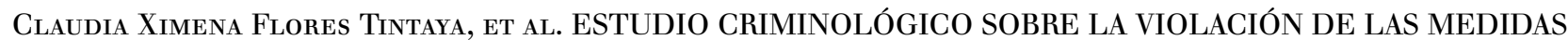
SANI...

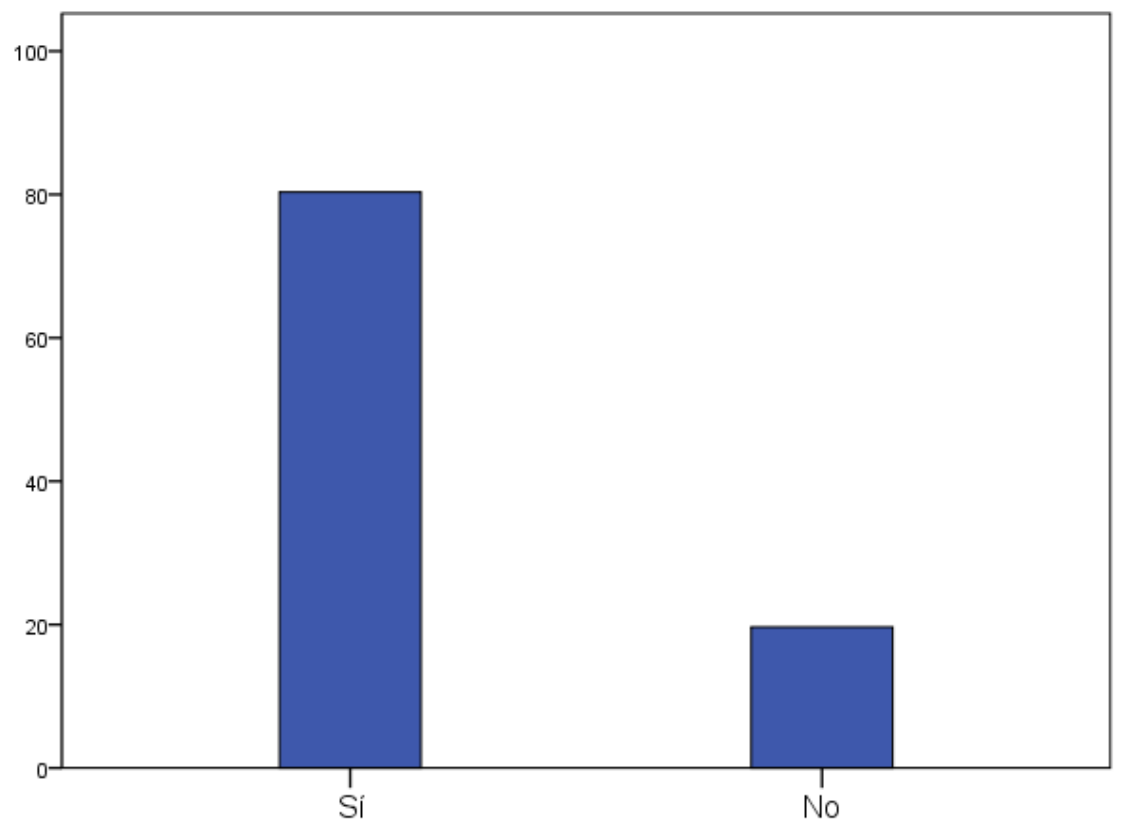

FIGURA 7

Ansiedad y estrés

Elaboración propia

TABLA 8

Ayuda Psicológica

\begin{tabular}{|c|c|c|}
\hline $\begin{array}{l}\text { ¿Sufrió de ansiedad o estrés durante } \\
\text { la Pandemia? }\end{array}$ & Frecuencia & Porcentaje \\
\hline Sí & 39 & 11,3 \\
\hline No & 307 & 88,7 \\
\hline Total & 346 & 100,0 \\
\hline
\end{tabular}

Elaboración propia 


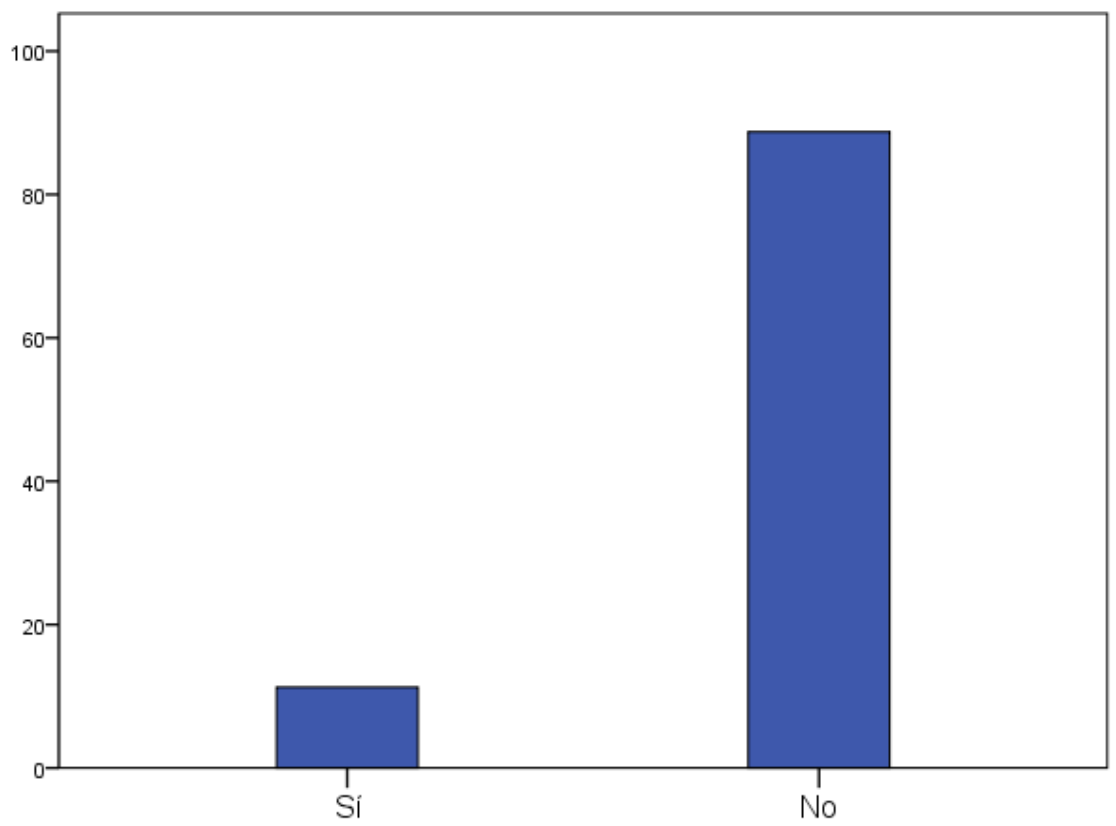

FIGURA 08

Ayuda psicológica

Elaboración propia

TABLA 9

Apoyo de Allegados

\begin{tabular}{lll}
\hline $\begin{array}{l}\text { Durante la cuarentena, }{ }_{2} \mathrm{Ha} \\
\text { solicitado ayuda o apoyo emocional } \\
\text { a sus amistades? }\end{array}$ & Frecuencia & Porcentaje \\
\hline Sí No & 158188 & $45,754,3$ \\
\hline Total & 346 & 100,0 \\
\hline
\end{tabular}

Elaboración propia 


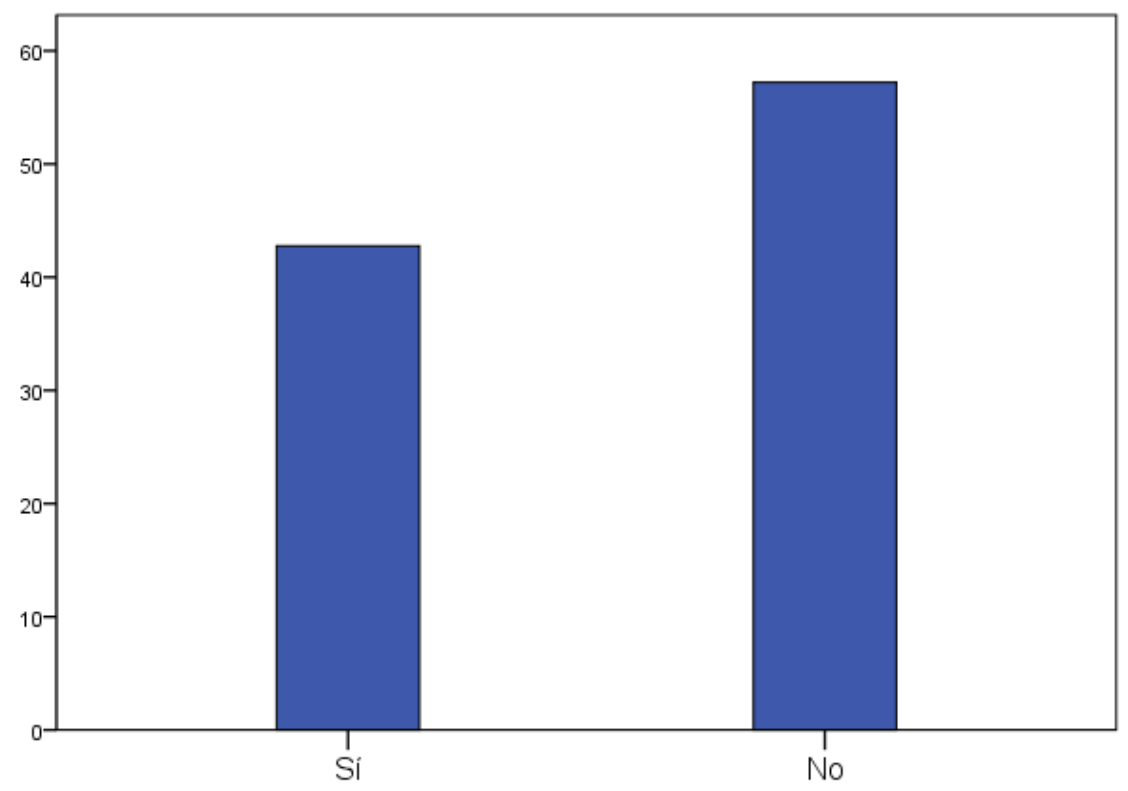

FIGURA 09

Apoyo de allegados

Elaboración propia

Del cuadro $\mathrm{N}^{\circ} 7$ con cifras 80.3 y $19.7 \%$ se desprende que cuatro de cinco personas han sufrido ansiedad durante el confinamiento, pero que a pesar de ello no han solicitado ayuda psicológica (Ver cuadro $\mathrm{N}^{\circ} 8$ ) y esto podría deberse a que, el ingreso que ellas percibían disminuyó en mayor o menor medida (Ver cuadro $\mathrm{N}^{\circ} 2$ ).

Sin embargo, cabe resaltar que la mayor parte de ellas no comunicaron su malestar a alguna de sus amistades (Ver cuadro $\mathrm{N}^{\circ} 9$ ) con lo que se concluye que, a pesar de requerir ayuda en el campo emocional, la mayoría de encuestados(as) no lo ha hecho aún si se tratase de sus allegados.

\section{DESARROLLO}

\section{A. EL COMPORTAMIENTO SOCIAL Y UN FACTOR BIOLÓGICO DE SU PAULATINO CAMBIO}

El comportamiento social o conducta social es el conjunto de actuaciones desarrolladas por un sujeto las cuales van dirigidas a la colectividad en cuanto ésta se refiere a su propia especie para generar influencia. Asimismo, para emprender su estudio se requiere conexionarlas con normas, valores y costumbres auténticos de la cultura en la que se presentan. Por ello se dice que lo idóneo o contraproducente del deber de comportamiento social se da en justificación al contexto donde se desarrolla. (Puerta Rodriguez, 2020)

Actualmente la enfermedad producida por el SARS-CoV-2 con un año aproximadamente de presencia en la vida de los seres que habitan el planeta, ha significado un cambio radical respecto de lo que era la concepción de normalidad para la humanidad porque lo ocasionado por ese microbio, vale decir cuarentenas (como ejemplo), que implican densos límites a los derechos, son incidentes agudos, estresantes, imprevistos lo que ha ocasionado la una interrupción en los procesos regulatorios de la vida social (Ritchie \& Gill, 2011). Pandemias como la COVID-19, son desastres de la biosfera en los que los microorganismos pueden cambiar o evolucionar y potencialmente conducir a una pérdida significativa de vidas, que es precisamente lo que está 
aconteciendo y lo que se busca prevenir o en su caso disminuir a través de confinamientos. (Hodgkinson $\&$ Andresen, 2020)

Ahora bien, el caso de nuestro país, Perú es bastante particular pues la conducta adoptada por la ciudadanía durante los primeros meses de la presencia de la pandemia, fue cambiando, con un inicio positivo acompañado de una declaratoria de emergencia temprana, a un desarrollo no tan eficaz como en el principio.

B. LA ALTERACIÓN DE LA PSICOLOGÍA SOCIAL DEBIDO LA PANDEMIA

Podemos inferir con respecto a la encuesta y tomando como base la psicología social como elemento principal en este apartado, que la ciudadanía a raíz de los problemas y adversidades que ha traído consigo la pandemia; su comportamiento psicológico está condicionado por cada uno de los factores tanto negativos como positivos, es decir, entre los negativos tenemos la falta de un empleo, o despido arbitrario, pérdida de un familiar, entre otros, ha provocado un grave grado de alteración o influencia de la sociedad atrayendo consigo comportamientos desviados al cumplimiento de la norma social, es decir, las actitudes se han visto envueltas de manera negativa. También, es preciso señalar que cada individuo que conforma nuestra sociedad siempre está en constante cambio y ese cambio se desencadena por una serie de factores como lo hemos visto durante todo el transcurso del año, cuando inició la pandemia.

La psicología social está siendo alterada en una gran mayoría entre unos y otros por la generación de atisbos en cuanto a la forma de vivir que se ha habituado este año, a pesar de poder contar con una serie de actividades en las cuales la persona podría realizar entre ellas la interacción de la familia más a menudo, la educación en casa, trabajo remoto, entre muchos otros que beneficien a su correcto desarrollo. Sin embargo, la sociedad no puede únicamente contar con ello, pues es preciso resaltar la relación con demás grupos humanos, y a falta de ello se ha incurrido en un sinfín de comportamientos sociales en contravención de la norma, en otras palabras, se generaron anomias a las medidas adoptadas por el Estado Peruano.

C. ASPECTOS QUE INFLUYEN EN EL ÁMBITO SOCIAL DURANTE LA PANDEMIA

La pandemia ha afectado a muchos países y ha causado la muerte de cientos de miles de personas sin discriminar entre ricos y pobres, jóvenes y ancianos, pero el virus no solo causa la muerte de las personas, sino que las ha afectado en varios muchos aspectos de la vida de las personas (laboral, educación, salud, etc.), luchando por sobrevivir, prácticamente obligando a todos a quedarse en casa durante toda la cuarentena.

Parece ser que uno de los desafíos más grandes que ha influenciado a las personas durante la pandemia y lo seguirá siendo en el periodo posterior. Hasta el día de hoy, este es un tema de preocupación para muchas personas, de manera que se impone restricciones y muchas responsabilidades, por lo que es muy difícil manejar este tipo de vida, debido a problemas económicos.

Durante la pandemia, que ha logrado encerrar a la mayoría de personas en sus hogares, cambio rutinas de vida, entre otras más.

Aspecto Laboral:

El brote Nacional hizo que muchas empresas e instituciones, por precaución, aceleraron la implementación de modelos laborales alternativos, anunciando que se iba a permitir a todos sus empleados trabajar desde sus casas a fin de evitar posibles contagios con la enfermedad. Igualmente, el ministerio del Trabajo propuso la iniciativa que insta a las empresas a parar actividades, existiendo riesgo "grave e inminente" de contagio.

Ahora una vez que ya se iba a permitió laborar desde sus hogares, existía otro desafío, en cuanto al trabajo online, un cambio repentino al trabajo digital remoto, experimentando nuevas experiencias, trasladar su vida laboral a internet de manera habitual.

Aspecto educativo

El gobierno ordenó el cierre de las escuelas a fin de prevenir mayores contagios. Medidas como estas alteran el calendario escolar de todas las escuelas involucradas.

En respuesta a una demanda significativa, muchas plataformas de aprendizaje en línea ofrecieron acceso gratuito a sus servicios, plataformas, se ha visto un aumento en el número de nuevos estudiantes que usan las 
plataformas virtuales. Pero también había estudiantes que no asistían a tiempo completo para reanudar sus estudios a través de plataformas en línea.

Con este cambio repentino fuera del aula algunos se preguntan si la adopción del aprendizaje en línea continuará persistiendo después de la pandemia y cómo tal cambio impactaría el mercado educativo, debido a que ya existe un h alto crecimiento y adopción en la tecnología de la educación.

Aspecto Psicológico

Con la rápida propagación del virus, muchas personas se encuentran encerradas en sus hogares, estas se sienten aburridas y sienten que sus movimientos son bastante limitados. Ven todo el tiempo noticias en donde les ofrecen información sobre el número de muertes en el mundo, sienten miedo a raíz de esto y creen que no están seguros y que estarán durante mucho tiempo en sus casas.

Esta pandemia nos lleva a todos a un estado de pesimismo, lo que resulta en una visión sombría sobre el futuro. Dicho estado de ánimo puede generar ansiedad por el futuro, el trabajo, cuestiones financieras, educación y, sobre todo, sobre la vida.

Para no seguir en esa rutina de vida, los miembros de la familia se ayudaron y apoyaron mutuamente, hablando y se escuchando, bromeando juntos, comerán juntos y pasarán tiempo, alentándose mutuamente no solo a olvidar el sentimiento de ansiedad del momento, sino también para darles una idea de que la vida continúa y que estos tiempos difíciles pronto pasarán.

En segundo lugar, como escuchamos en la televisión y vemos a nuestro alrededor, por ejemplo, muchas personas han perdido sus trabajos; algunos han tenido que tomar licencias no remuneradas y los salarios de muchos otros se han reducido debido al cierre de muchas empresas

La familia se convirtió en una fuente de apoyo financiero y físico durante el tiempo de la pandemia, apoyándose mutuamente en la parte financiera, comparten lo que tienen hasta que termine la pandemia, con lo que el espíritu de solidaridad, protección y pertenencia a un hogar estable les permite ponerse de pie y sobrevivir en estos tiempos difíciles.

De esta manera, reducen el costo de la vida y el costo del alquiler junto con el costo del gas, electricidad y agua, cuyos precios han aumentado, dramáticamente durante la pandemia.

D. CARACTERÍSTICAS DE A CONDUCTA ANTISOCIAL

La conducta antisocial es la que implica la trasgresión de una norma social, cualquier conducta delictiva es antisocial, ya que transgrede una norma escrita. La persona antisocial se caracteriza por trasgredir las normas de todos los niveles. No obstante, el que todas las conductas delictivas sean antisociales no quiere decir que todas las conductas antisociales sean delictivas, al igual que no es necesario que estén escritas para ser antisociales. (Carbonell \& Beleña, 2012)

Desde el punto de vista de una continuidad heterotípica, un individuo tiene una característica que hace que sea predecible que transgreda las normas, entonces la primera característica será que salte las normas, pero de manera regular a lo largo del tiempo y en diferentes contextos. Por ejemplo, si uno es infiel, pero no se salta otra norma y no es habitual, pues no sería representativo. Tiene que haber reiteración a lo largo del tiempo y tiene que haber una continuidad interinstitucional. Viola las medidas impuestas en su hogar, falta al compromiso con sus jefes, con los padres, viola las normas impuestas por autoridad, es una persona que no respeta los compromisos. Eso caracteriza un sujeto antisocial.

Es importante hacer mención a el rasgo, pues indica los hábitos que tienen cierta estabilidad, pero no se puede asegurar que sean para el resto de la vida del individuo, sin embargo, el rasgo se puede plasmar en la tendencia a evitar responsabilidades, tendencia a maximizar la inmediata gratificación, control emocional o atenuación emocional, uso adolescente (conducta aversiva frecuente para controlar el entorno) y carrera delictiva. De las cinco características las más importante son las tres primeras; cuando se habla de rasgo antisocial se hace referencia a que cumple mencionadas características, a saber, evitar responsabilidades, maximizar la inmediata gratificación y control emocional o atenuación emocional.

E. LAS MEDIDAS SANITARIAS QUE SE DIERON AL INICIO DE LA PANDEMIA 
$\mathrm{Al}$ inicio de la pandemia registrada como tal en nuestro país Peruano se optaron por diversas medidas sanitarias para poder contrarrestar el nivel de contagio y de esta manera neutralizar el virus y no llegar de manera abrupta a la ola más alta, lo cual era inevitable en cierto modo, es menester formularnos la siguiente pregunta; ¿fueron eficaces estas medidas sanitarias adoptadas por el gobierno?, bueno para responder la misma debemos primero plantear cuales fueron las medidas adoptadas por nuestro gobierno Peruano.

Tras el anuncio del primer caso de COVID-19 confirmado en nuestro país, Martin Vizcarra, presidente de la republica anuncio las medidas adoptadas por su gobierno para enfrentar la COVID-19, se expresó de la siguiente manera, "como gobierno evaluamos responsablemente la situación y hoy aprobamos en el consejo de ministros un decreto de urgencia, que establece medidas extraordinarias para adoptar acciones preventivas y de respuesta para reducir la propagación del virus en el territorio Nacional”. (República, 2020)

Las medidas sanitarias fueron las siguientes:

$\varnothing$ Declarar Estado de emergencia

$\varnothing$ Decreto el 16 de marzo del 2020, una cuarentena general, en el país durante 15 días, pero a medida que aumentaba los casos positivos se incrementó los días de cuarentena obligada.

$\varnothing$ El cierre de sus fronteras durante un lapso de 15 das para combatir la pandemia, pero con el transcurso del tiempo y el incremento de casos se fueron ampliando las fechas,

$\varnothing$ Se restringió eventos o actividades, de manera absoluta debido al aislamiento social.

$\varnothing$ Medidas de higiene.

$\varnothing$ Se declaro el toque de queda, en el horario establecido de acuerdo al nivel de contagio de cada departamento.

De esta manera se dictaron las medidas sanitarias, ahora bien al responder la pregunta formulada anteriormente, para dar respuesta a ella nos enfocaremos en los resultados de la encuesta empleada, y se observa en la figura número 1, lo siguiente; en primer lugar, las personas consideran que las medidas sanitarias fueron malas un total de $44,8 \%$, en segundo lugar., consideran que fueron buenas un total de $42,8 \%$ y en tercer lugar, consideran que son muy malas un total de $11.3 \%$, de esta manera podemos evaluar que las personas consideran que la medidas adoptadas fueron malas porque no fueron eficaces.

\section{F. MOTIVO DE LA VIOLACIÓN DE LA NORMA}

Una norma jurídica es un mandato o regla cuyo objetivo es el de dirigir el comportamiento de las personas dentro de la sociedad, en tal sentido es preciso mencionar que:

"La norma jurídica es una regla u ordenación del comportamiento humano dictado por la autoridad competente del caso, con un criterio de valor y cuyo incumplimiento lleva a una sanción. Generalmente, impone deberes y confiere derechos. Se trata de una regla o precepto de carácter obligatorio, emanado de una autoridad normativa legitimizada, la cual tiene por objeto regular las relaciones sociales o la conducta del hombre que vive en sociedad"(Creosltda.com)

¿POR QUÉ SE VIOLA O TRANSGREDE UNA NORMA JURÍDICA?

$\mathrm{Al}$ respecto, podemos sostener dos posiciones para tratar de responder tal interrogante.

1.- Contenido de Valor de la norma jurídica:

En virtud de esta posición, (Rodríguez Chávez)sostiene que las violaciones o transgresiones de las normas jurídicas no son sino el producto del contenido de valor que posean. Si el valor que contiene una norma jurídica es considerado como bueno por la comunidad, entonces, la norma jurídica será aceptada y, consecuentemente respetada por todos. En caso contrario, si el contenido de valor de una norma jurídica contradice el valor general, el valor común de la sociedad, entonces, devendrá inevitablemente la violación de la norma jurídica. En conclusión, del contenido de valor que posea la norma jurídica, dependerá su violación o transgresión, o en su caso, su respeto u observancia.

2.- Cultura violenta del hombre:

Una segunda posición de (Rodríguez Chávez) sostiene que el origen de tales violaciones radica en la cultura violenta del hombre. Desde que puso los pies sobre la tierra, el hombre siempre ha querido ir más allá de lo 
permitido, en la esencia misma del hombre se halla aquella inclinación por romper todo tipo de limitaciones, todo tipo de parámetros entre ellos las normas jurídicas que el hombre casi intuitivamente viola o transgrede. En tal sentido, al existir la norma jurídica, se convierte en una suerte de “manzana de Adán”, en una tentación que llama al hombre a violarla o simplemente no cumplirla.

3.- La anomia social de Durkheim

Por otro lado, podemos hacer mención al concepto de la anomia, introducido por Émile Durkheim, la misma que se encuentra muy vinculada y relacionada a la ausencia del cumplimiento de las normas estructuradas en una sociedad y más si se trata en un contexto generalizado, es decir, de la colectividad y por ello se puede hacer alusión al término "estado de desorden" para entender mejor el significado de anomia como bien lo hacía Durkheim.

Por mucho tiempo el significado de Anomia viene siendo relacionado con criminalidad y el delito en concreto. Tanto la persona criminalizadora como el personaje activo que comete algún delito vienen estrechamente enfocados en torno a la anomia, es decir, la falta al cumplimiento de las normas de ley lo que de cierta forma se puede explicar con los dos postulados anteriormente señalados.

4.- El ser humano es un ser social por naturaleza

Aristóteles dice que nacemos con características sociales y las vamos desarrollando a lo largo de nuestra vida ya que necesitamos de otros para sobrevivir. El hombre necesita vivir en sociedad, ya que el hombre racional e individual no es autosuficiente y requiere de la ayuda y protección de los demás, de su especie, formando lo que llamamos comunidades.

5.- Las necesidades humanas (Maslow)

La pirámide de Maslow o también llamada jerarquía de las necesidades humanas es una teoría creada por el psicólogo estadounidense Abraham Maslow, la cual publicó en 1943 en su libro: una teoría sobre la motivación humana. "La teoría de la pirámide de Maslow afirma que las acciones del ser humano nacen de una motivación innata a cubrir nuestras necesidades, las cuales se ordenan jerárquicamente dependiendo la importancia que tienen para nuestro bienestar"(Espinoza)

Las necesidades del ser humano se jerarquizan y categorizan se de acuerdo a la importancia e incidencia que tienen en nuestras vidas. Maslow propuso una pirámide de necesidades que explica qué impulsa a la conducta humana. Esta pirámide se divide en cinco niveles que van desde aspectos más básicos como la supervivencia, hasta motivaciones más complejas como el crecimiento personal.

En el primer nivel de la pirámide se encuentran las necesidades más básicas como alimentarse o descansar, únicamente avanzaremos al siguiente nivel, una vez que hayamos cubierto las necesidades del nivel en el que nos encontremos, y así sucesivamente hasta llegar al último nivel.

"Necesidades Fisiológicas. El primer nivel de la pirámide son las necesidades fisiológicas. Son las más básicas, tales como respirar, hidratarse, alimentarse, descansar, protegerse y reproducirse. Todas aquellas necesarias para la supervivencia del ser humano" (Espinoza, $\mathrm{sf}$ ).

Necesidades de Seguridad. El segundo nivel de la pirámide de Maslow son las necesidades de seguridad. Son todas aquellas relacionadas con la seguridad y estabilidad de una persona, es decir, seguridad física y saludable, de empleo, de ingresos, de recursos, seguridad moral y familiar, y de propiedad privada (Espinoza, sf).

"Necesidades Sociales. El tercer nivel de la pirámide son las necesidades sociales. También conocidas como de afiliación y afecto, entre ellas se puede encontrar el desarrollo afectivo, la asociación, la aceptación, el afecto o la intimidad sexual" (Espinoza, sf).

IV. ANÁLISIS DEL TIPO PENAL: VIOLACIÓN DE MEDIDAS SANITARIAS - ARTÍCULO $292^{\circ}$

El delito de violación de medidas sanitarias, es una figura típica que tiene rasgos de prevención que, trae como consecuencia penal frente a la infracción o violación de medidas sanitarias que son impuestos por ley o autoridad competente a fin de que la ciudadanía tome precauciones o respete ciertas medidas impuestas por el estado, frente a situaciones que se requiere prevenir enfermedad, epidemia, epizootia o plaga, que podrían asechar a la salud y la vida. (Espinoza Guzmán, 2020). 
Es importante hacer mención que, se tutela un bien jurídico de carácter supraindividual, cuyo interés rebaza la simple implicancia de afectaciones particulares y llega a un interés colectivo. Se aduce que la violación a las medidas sanitarias constituiría un delito de contexto, los delitos de contexto son aquellos que conforme a un tiempo determinado o temporada precisada por la norma penal es viable la configuración del tipo penal, es decir, obtienen idoneidad delictiva por el contexto en el que es posible su ejercicio conductual. (García Navarro, 2020)

Ahora bien, el delito de violación de medidas sanitarias es un tipo penal en blanco, ya que para su configuración no es solo suficiente el simple incumplimiento de las medidas sanitarias impuestas, se requiere, además, que esta trascienda al incumplimiento de leyes o reglamentos que han sido dispuestos por una autoridad competente, en donde el sujeto activo de la conducta, pone en riesgo o peligro al bien jurídico de la salud pública. Es importante agregar que, no se requiere que a través de este delito el agente cause algún tipo de lesión, ya que, al ser un delito de peligro abstracto, implica que con solo la violación de medidas sanitarias el agente cause la puesta o incremento de peligro del bien jurídico protegido. (Zevallos Prado, 2020)

Entonces, lo que se busca a través del tipo penal de violación de medidas sanitarias es castigar a aquel sujeto que no cumple, viola o infringe la norma, haciendo caso omiso a las medidas sanitarias que han sido impuestas por ley o por autoridad competente; en el caso en particular se publicó el Decreto Supremo No 044-2020PCM, donde se declaró Estado de Emergencia Nacional por las graves circunstancias que afectan la vida de la Nación a consecuencia del brote del COVID-19. Ahora bien, al respecto el Poder Ejecutivo publicó el Decreto Legislativo $\mathrm{N}^{\circ} 1458$, mediante el cual brinda el marco legal para sancionar el incumplimiento de las disposiciones emitidas durante la emergencia sanitaria a nivel nacional y demás normas para proteger la vida y la salud de la población, del mismo modo, publicó su reglamento plasmado en el Decreto Supremo N ${ }^{\circ}$ 006-2020- IN; en donde establece en su artículo $4^{\circ}$; que la responsabilidad administrativa del infractor es independiente de la responsabilidad civil o penal que pudiera originarse por las acciones u omisiones que a su vez configuran la infracción administrativa.

Por otra parte, no toda medida sanitaria es pasible de sanción penal, sino solo aquellas conductas que atenten, pongan en peligro o en riesgo al bien jurídico protegido, el mismo que no necesita de ningún resultado concreto que ocasione el agente, basta con la puesta en riesgo o peligro al mismo. (Espinoza Guzmán, 2020)

El tipo penal de violación de medidas sanitarias, expresamente establecido en el artículo $292^{\circ}$ del Código Penal peruano, presenta preceptos o supuestos, por ello, es menester su análisis para poder realizar la subsunción o calificación de las conductas; es así que se encuentra el elemento objetivo del tipo penal, en donde concurren supuestos como; el contexto de medida sanitaria, la introducción de enfermedad, epidemia, epizootia o plaga, la orden expresa y autoridad que decreta las medidas sanitarias y. la verificación de la infracción o violación a través del complemento legal.

Como se ha venido tratando, en cuanto al bien jurídico protegido, en el caso, vendría a ser la Salud Pública, ahora bien, la Salud Pública se entiende como aquella salud de todas las personas que se ven potencialmente afectadas por la introducción o propagación de una epidemia en el país donde residen, del mismo modo, la Salud Pública, es una necesidad por parte del estado de preservar la vida frente a situaciones difíciles que se podría atravesar. Lo cierto es que, a través de la conducta que pone en riesgo a la Salud Pública, también se afecta a la vida, puesto que se ve en riesgo o peligro por la mortalidad y los efectos que podría generar algún tipo de enfermedad.

Debe señalarse, además, el sujeto activo, se hace referencia al precepto "el que", implicando que el delito puede ser cometido por cualquier sujeto; es decir, que para la configuración típica del delito no se requiere que el autor sea un sujeto cualificado, se tratas así de un delito común. Por otro lado, el sujeto pasivo del delito es el Estado, el que puede ser representado por el Ministerio de Salud, se entiende que la parte afectada va ser por la puesta en riesgo o peligro al bien jurídico protegido, es decir, la Salud Pública. 
Otro de los elementos importantes del tipo es la tipicidad subjetiva, la violación de medidas sanitarias supone un conocimiento y voluntad por parte del agente, es decir, actúa con dolo, ya que se tiene conocimiento pleno de las medidas sanitarias impuestas por la autoridad o ley, no obstante, el delito de violación de medidas sanitarias también puede ser cometido por acción por omisión, en donde el agente asumen un deber especial, y no hace lo que debería hacer, conforme a lo dispuesto por un mandato de la autoridad o ley, entonces infringe la norma prohibitiva.

Finalmente, el delito de violación de medidas sanitarias, como se mencionó en la primera parte de este aparatado, es un delito de peligro abstracto, y estos son entendidos como aquellos que no se requiere que la acción haya ocasionado un daño sobre un objeto, sino que basta con que el objeto jurídicamente protegido haya sido puesto en peligro de sufrir la lesión que se quiere evitar, es por ello, que el delito se consuma con la sola puesta en peligro del bien jurídico protegido por parte del agente, no siendo necesario la existencia de un resultado concreto como consecuencia de la infracción de las medidas sanitarias.

\section{FACTORES A CONSIDERAR EN LA ELABORACIÓN DE UNA POLITICA PÚBLICA}

- Trabajadores informales.- Trabajadores informales. - El Instituto Nacional de Estadística e informática (INEI), informó el 15 de mayo del 2019, que en el Perú existe una cantidad de 239000 personas que obtuvieron un empleo informal en un porcentaje de $72,8 \%$ de la población total a diferencia del empleo formal urbano donde el crecimiento es relativamente equitativo entre los distintos grupos de edad. Ahora bien, en el año 2020, la Pandemia del Covid-19 ha agudizado la informalidad laboral y económica bordeando el $90 \%$. La cuarentena aplicada entre abril y julio dejó 6.7 millones de desempleados. La informalidad que caracteriza al mercado laboral peruano es, en principio, la insuficiencia de oferta y, en segundo lugar, la magnitud del desempleo abierto. En ese orden de ideas, si se parte de la hipótesis de que la informalidad es un fenómeno multisectorial, significa que no es existe una única solución para reducirla, es menester la aplicación de políticas públicas que tengan repercusión sobre dicha problemática, por ejemplo, reformas laborales, la legislación laboral en el Perú es rígido y ello impide el empleo formal, los costos de creación de empleo formal, son incentivos de la informalidad.

- Situación política.- El Presidente del año 2018 fue Martin Vizcarra por sucesión en razón de la renuncia del ex presidente PPK, y fue quien tomó las riendas del país al inicio de la pandemia, su gobierno adopto diversas medias sanitarias y políticas. Posteriormente a ello el presidente se encontró en algunos actos que podrían ser denotados como irregulares, debido a ello el Congreso de la República decide presentar hasta dos mociones de censura contra en el mandatario y fue la segunda quien determina la vacancia del entonces presidente de la república Martin Vizcarra. Entonces quien toma la rienda del país peruano fue Manuel Merino de Lama con un nuevo gabinete quien gobernó menos de una semana debido a que la oblación percibió que hubo una toma ilegitima del poder y mediante multitudinarias marchas instigaron a la renuncia del mismo y de esta manera el congreso se ve obligado a escoger un nuevo presidente de entre sus miembros y quien fue elegido es Francisco Sagasti, el mandatario actual instauro un nuevo gabinete.

El cambio de presidentes conjuntamente con el consejo de ministros que cada mandatario instauro, en tiempo de pandemia, ha afectado indirectamente a las medidas que se pudieron adoptar para contrarrestar la propagación del virus. Muchos medios internacionales hicieron alusión en cuanto al cambio de mandatarios que era el peor momento de enfrentar una crisis política debido a que en ese momento se vivía una crisis sanitaria.

- Equipamiento del sistema de salud Nacional.- Las necesidades en salud se han evidenciado por el desabastecimiento de materiales, hospitales viejos, laboratorios especializados, camas, ventiladores, especialistas; conllevando consigo otros problemas como población geriátrica en 
completo abandono, médicos mal remunerados, sin seguro médico. Además, medidas adoptadas como las de bioseguridad son poco eficaces y carentes de equitación. La reforma en cuento al sistema de salud Nacional necesita apuntar hacia un sistema único y universal para la salud, donde se vea ordenado y coordinado, donde se retome el rol del Rector del Ministerio de Salud, apuntando a conseguir mejores laboratorios modernos integrados con una excelente calidad de servicio que beneficie a la Sociedad Peruana.

- Asistencia psicología gratuita.- Sentir ansiedad, nerviosismo, agitación, tristeza o ira, entre otras emociones, es normal frente a situaciones tan extremas como la que estamos atravesando con la pandemia por el covid-19 y la situación de confinamiento que supone, se trata de reacciones normales frente a situaciones inusuales y de crisis grave que suponen afrontar niveles extremos de incertidumbre y estrés. Lo que se recomendó es mantener contacto a través de videollamadas con amigos y familiares de manera que ayuda a vencer el aislamiento, cuidar el bienestar físico ya sea tratando de realizar ejercicios, comer saludablemente, cuidar del sueño, crear una rutina diaria participando en actividades útiles o actividades significativas, mantener la mente activa, realizar cosas que disfrute en casa, ver cursos gratuitos en línea.

\section{CONCLUSIONES DE LA ENCUESTA REALIZADA}

Como una deducción de esta encuesta realizada, se ha hallado que las personas residentes en la ciudad de Puno habrían infringido las normas sanitarias impuestas por el Gobierno por motivos que radican principalmente en la necesidad del sustento económico lo cual nos conduce a afirmar que el Gobierno no ha planteado de una manera adecuada sus políticas respecto de esta cuarentena.

Asimismo, como segunda deducción de esta encuesta, que debemos tomar en cuenta necesariamente es que en el cuadro $\mathrm{N}^{\circ} 6$ se indica que el $42.8 \%$ de los encuestados ha infringido la norma al asistir a compromisos sociales lo que conduce a preguntarnos en el poco interés de casi la mitad de la población de acatar las normas impuestas por el gobierno.

\section{CONCLUSIONES}

El presente trabajo de investigación fue desarrollado con la intención de conocer y sobre todo comprender el comportamiento de los ciudadanos en el Perú, en nuestro caso fue el que es natal de Puno pues la encuesta fue remitida al círculo social de los investigadores. Llama bastante la atención que en una de las preguntas de la encuesta la mayoría de los participantes acorde a las alternativas escogiera que no estuvo de acuerdo con las medidas emitidas por el Gobierno, ello junto a otra pregunta referida a la situación económica en la cual la mayoría escogió la opción de que se vieron afectados económicamente lo cual nos remite a la conclusión de que el Estado no ha planteado políticas públicas adecuadas para la población. En ese sentido es importante que el Estado estudie mejor las decisiones que emitirá y esencialmente realice sus estudios con visión a futuro pues de esa manera podrá percibirse una respuesta positiva de una nación y en situaciones tan delicadas como la actual, más aún. Una persona no necesita de apoyo cuando este es realmente insuficiente, sino que el estado le brinde una serie de mecanismos para un sustento adecuado en los cuales se prioricen de la misma manera la economía y la salud, ambas cosas a la vez, lo cual puede ser complicado al ser un país tan heterogéneo, pero no imposible.

La psicología social estudia las relaciones sociales que se dan a base de la interacción, y como están influyen y van a modificar la conducta, los sentimientos, los pensamientos de las personas de nuestra región lo cual se evidencia en la encuesta realizada de la cual se desprende que un $45,7 \%$ de las personas piden ayuda emocional a sus allegados, por el cual se evidencia la influencia del entorno social tiene en una persona. 
La criminología conductual es una rama de la criminología que nos ha ayudado en el proceso de adaptación de las personas durante la pandemia ocasionada por el COVID-19, que trajo consigo consecuencias en diferentes aspectos. En primer lugar, el aspecto laboral, en la perdida de los puestos laborales en un sector de la población, otro porcentaje de la población tuvo que adaptarse a un trabajo remoto, experimentando nuevas experiencias. Otro aspecto afectado fue la educación, debido a que el gobierno tomó medidas para evitar la proliferación de la enfermedad y estas fueron; el cierre de todos los centros educativos en todos los niveles y si implemento la educación virtual, sin embargo, un gran porcentaje de estudiantes se vio afectado debido a la falta de acceso a internet y ello causo una fuerte afectación respecto a la educación. Por último, es importante hacer mención al aspecto psicológico, debido a que la pandemia tuvo más repercusión en este aspecto, por ejemplo, en las encuestas demostraron, la mayor parte sufrió de estrés y angustia, no obstante no recurrieron a la ayuda de un psicólogo, sin embargo buscaron apoyo en amigos o familiares.

En lo que respecta a la psicología criminal, como sabemos que es una rama que estudia el porqué del comportamiento delictivo, ahora bien en relación a la violación de normas durante la pandemia ocasionada por la COVID-19, se puede llegar a la conclusión de que las medidas impuestas por el estado fueron vulneradas, el primer factor fue la economía, puesto que hubo una pérdida masiva de empleos, como consecuencia existió la vulneración a la ley, otro factor fue el aspecto psicológico, las personas sentían estrés y angustia y ello ocasionó que puedan realizar reuniones y del mismo modo hubo la violación al mandato de la autoridad, asimismo influyo el rasgos de cada individuo, puesto que este rasgo caracteriza el pensar de cada uno, es así que un porcentaje de los encuestados tomo una posición negativa frente a las medidas sanitarias impuestas por el gobierno.

Las medidas sanitarias son un conjunto de actuados por una autoridad sanitaria, que tiene por finalidad controlar o eliminar un evento que atente con la vida de todos. En nuestro país se adoptaron diferentes medidas Par contrarrestar o eliminar el virus COVID-19, lo cual no fueron acertados porque así lo considera la población mediante la encuesta realizada.

La violación de las medidas sanitarias puede ser explicada por los siguientes aspectos:

1. Las violaciones o transgresiones de las normas jurídicas no son sino el producto del contenido de valor que posean, del contenido de valor que posea la norma jurídica, dependerá su violación o transgresión, o en su caso, su respeto u observancia, lo cual se relaciona con el hecho que un $44,8 \%$ de las personas encuestadas consideran malas, las medidas sanitarias impuestas por el Estado por ende tendrán la tendencia a no cumplirla.

2. Según la Anomia Social de Durkheim hace referencia la ausencia del cumplimiento de las normas estructuradas en una sociedad y más si se trata en un contexto generalizado, es decir, de la colectividad y por ello se puede hacer alusión al término "estado de desorden" en el cual se da una suerte de desprecio a la norma jurídica, por lo que concluimos que respecto a las personas encuestadas solo un $42,8 \%$ consideran buenas las medidas sanitarias, por ende el porcentaje restante tiene una suerte de desprecio por la norma jurídica.

3. Aristóteles dice que nacemos con características sociales y las vamos desarrollando a lo largo de nuestra vida ya que necesitamos de otros para sobrevivir. El hombre necesita vivir en sociedad, ya que el hombre racional e individual no es autosuficiente y requiere de la ayuda y protección de los demás, de su especie, formando lo que llamamos comunidades por tal razón afírmanos que el ser humano necesita estar en relación constante con sus semejantes y busca la manera de hacerlo de forma remota, pero un algunos caso se dieron las reuniones sociales en un $42,8 \%$ de las personas encuestadas, en el fana de las personas de estar en siempre en su estado de socialización.

4. La teoría de la pirámide de Maslow afirma que las acciones del ser humano nacen de una motivación innata a cubrir nuestras necesidades, las cuales se ordenan jerárquicamente dependiendo la importancia que tienen para su bienestar de los cuales podemos hacer mención a los tres primeros niveles las cuales son causas obvias del incumplimiento de las medidas sanitarias, las más básicas, tales como respirar, hidratarse, alimentarse, descansar, protegerse y reproducirse; el segundo nivel se refiere a todas aquellas relacionadas con la seguridad y estabilidad de una persona, es decir, seguridad física y saludable, de empleo, de ingresos, de 
recursos, seguridad moral y familiar, y de propiedad privada; el tercer nivel de la pirámide son las necesidades sociales.

\section{REFERENCIAS}

Carbonell, E., \& Beleña, A. (2012). Psicología Criminal.

Corbolán Berná, J., \& Patró Hernández, R. (2006). Introducción a la Psicología Criminal (pp. 2-4).

Creosltda.com. (n.d.). http://www.creosltda.com . http://www.creosltda.com/creos2/images/PDF/6norma1.pdf

Crespo Suarez, E. (1995). Introduccion a la psicologia social.

El Diario del Exportador. (2017). El Diario del Exportador. https://www.diariodelexportador.com/2017/12que-es-e l-acuerdo-de-medidas-sanitarias.html? $\mathrm{m}=1$

Espinoza, R. (n.d.). obertoespinosa.es. https://robertoespinosa.es/2019/06/09/piramide-de-maslow\#: :text=El primer nivel de la pirámide son las necesidades fisiológicas,la supervivencia del ser humano.\&text=El segundo nivel de la,son las necesidad

Hodgkinson, T., \& Andresen, M. (2020). Show me a man or a woman alone and I'll show you a saint: Changes in the Journal of Criminal Justice.

Invima. (1993). Institución Nacional de Vigilancia de Medicamentos y Alimentos: una muerte anuniada.

Montero, M. (2010). Vidas paralelas: Psicologia comunitaria en latinoamerica y en Estados Unidos. In Psicologia Social Comunitaria. (pp. 1-15).

Observatorio de Política Criminal. (2015).www.politicacriminal. http://www.politicacriminal.gov.co/Portals/0/doc umento/queespoliticacriminal-ilovepdf-compressed.pdf

Puerta Rodriguez, A. (2020). Lifeder.com. https://www.lifeder.com/comportamiento-social/

República, P. de la. (2020). Organización Panamericana de la Salud.https://www.paho.org/per/index.php?option=co m_content\&view=article\&id=4494:peru-presidente-de-la-republica-anuncio-medidas-para-enfrentar-el-covi d-19\&Itemid $=0$

Ritchie, L., \& Gill, D. (2011). Considering community capitals in disaster recovery and resilience. PERI Scope (Public Entity Risk Institute).

Rodríguez Chávez, R. (n.d.). https://www.derechoycambiosocial.com . https://www.derechoycambiosocial.com/RJC/ Revista13/norma.htm

Soria Verde, M. A., \& Roca Sáiz, D. (2005). Psicología Criminal.

Valdivia Velez, G. (2020). Andina.pe. https://andina.pe/agencia/noticia-jorge-yamamoto-mayoria-los-peruanos-tien e-un-serio-problema-comportamiento-810857.aspx 